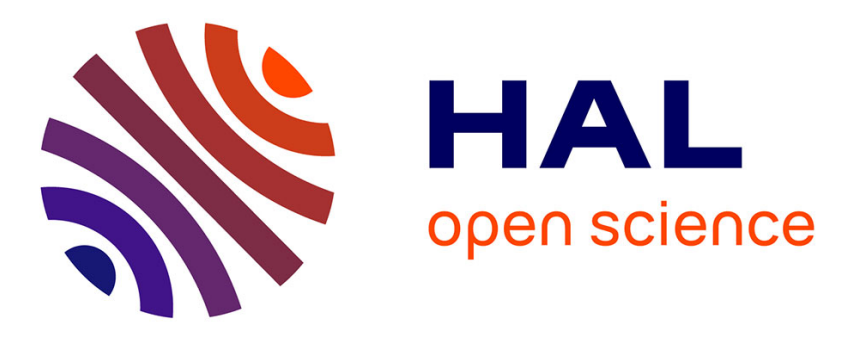

\title{
Tuning the structure of 1,3,5-benzene tricarboxamide self-assemblies through stereochemistry
}

Xavier Caumes, Arianna Baldi, Geoffrey Gontard, Patrick Brocorens, Roberto

Lazzaroni, Nicolas Vanthuyne, Claire Troufflard, Matthieu Raynal, Laurent Bouteiller

\section{To cite this version:}

Xavier Caumes, Arianna Baldi, Geoffrey Gontard, Patrick Brocorens, Roberto Lazzaroni, et al.. Tuning the structure of 1,3,5-benzene tricarboxamide self-assemblies through stereochemistry. Chemical Communications, 2016, 52 (91), pp.13369 - 13372. 10.1039/C6CC07325E . hal-01394304

\section{HAL Id: hal-01394304 https: / hal.sorbonne-universite.fr/hal-01394304}

Submitted on 9 Nov 2016

HAL is a multi-disciplinary open access archive for the deposit and dissemination of scientific research documents, whether they are published or not. The documents may come from teaching and research institutions in France or abroad, or from public or private research centers.
L'archive ouverte pluridisciplinaire HAL, est destinée au dépôt et à la diffusion de documents scientifiques de niveau recherche, publiés ou non, émanant des établissements d'enseignement et de recherche français ou étrangers, des laboratoires publics ou privés. 


\title{
Journal Name
}

\section{Tuning the structure of 1,3,5-benzene tricarboxamide self- assemblies through stereochemistry ${ }^{\dagger}$}

\author{
Xavier Caumes, ${ }^{a}$ Arianna Baldi, ${ }^{a}$ Geoffrey Gontard, ${ }^{\text {a }}$ Patrick Brocorens, ${ }^{b}$ Roberto Lazzaroni, ${ }^{b}$ Nicolas \\ Vanthuyne, ${ }^{c}$ Claire Troufflard, ${ }^{a}$ Matthieu Raynal ${ }^{a}{ }^{a}$ and Laurent Bouteiller ${ }^{a}$
}

\begin{abstract}
A heterochiral 1,3,5-benzene tricarboxamide (BTA) monomer, derived from valine dodecyl ester, forms long rods in cyclohexane whilst its homochiral analogue assembles into dimers only at the same concentration. This highly original assembly behaviour is related to the destabilization of the dimeric structure containing the two heterochiral monomers as corroborated by a combined experimental and computational study.
\end{abstract}

The non-symmetrical spatial arrangement of functional organic molecules in self-assembled systems yields chiral supramolecular structures with new functions compared to the simple, non-associated, building blocks. ${ }^{1}$ Controlling the structure and chirality of synthetic assemblies in solution is of prime importance for their applications in chiral recognition and sensing, ${ }^{1 e, 2}$ in separation processes, ${ }^{3}$ or as chiroptical switches, ${ }^{1 \mathrm{e}, 4}$ optoelectronic materials, ${ }^{1 \mathrm{e}, 5}$ and asymmetric catalysts. ${ }^{6}$

The aggregation of an enantiopure monomers into a welldefined chiral one-dimensional (1D) nanostructure in solution is usually programmed at the molecular level and executed during the self-assembly process. ${ }^{7}$ However, as the assembly relies on dynamic non-covalent interactions, complex selfassembly pathways also exist for which a single monomer may aggregate into morphologically-different chiral supramolecular structures (finite entities or polymeric 1D filaments, helices, nanotapes, nanotubes...). In such cases, tuning experimental conditions such as concentration, ${ }^{8}$ temperature, ${ }^{9}$ time (kinetics), ${ }^{10}$ solvent, $^{11}$ light $^{9,12}$ and additives ${ }^{13}$ results in the selection of a predominant aggregate. Changing the stereochemistry of the interacting monomers, for example by using a scalemic mixture of monomers, mainly serves in the purpose of unveiling chirality amplification ${ }^{1 \mathrm{~b}}$ and self-sorting ${ }^{14}$

\footnotetext{
a. Sorbonne Universités, UPMC Univ Paris 06, CNRS, Institut Parisien de Chimie Moléculaire, 4 Place Jussieu, F-75005 Paris, France. matthieu.raynal@upmc.fr

${ }^{b}$ Service de Chimie des Matériaux Nouveaux, Université de Mons/Materia Nova, Place du Parc, 20, B-7000 Mons, Belgium

c. Aix Marseille Univ, CNRS, Centrale Marseille, iSm2, Marseille, France

tElectronic Supplementary Information (ESI) available: General procedures,

synthesis and characterization of ester BTAs, Fig. S1 to S15, Table S1 and

crystallographic data. See DOI: 10.1039/x0xx00000x
}

processes. Racemic mixtures of monomers may assemble into fibrillar networks different from those formed by their homochiral stereoisomers ${ }^{15}$ but rarely leads to drastic changes in the nature of the chiral nanostructures (e.g. finite vs long helical aggregates). ${ }^{16}$ Efforts are required to design supramolecular assemblies which can adopt various welldefined chiral nanostructures by simply changing the stereochemistry of its interacting components.

Heterochiral monomers, i.e. monomers containing chiral centres of opposite chirality, inherently conduct to heterochiral assemblies since these monomers cannot be deracemized at the supramolecular level. ${ }^{15 c, 17}$ Contrary to our expectations, the heterochiral monomer of a BTA derived from valine dodecyl ester (BTA $(\boldsymbol{S}, \boldsymbol{S}, \boldsymbol{R})$-Val, Chart 1 ) assembles into long helical rod-like objects while the corresponding homochiral monomer (BTA (S)-Val) only forms dimers at the same concentration. In this work, the factors that conduct the heterochiral monomer to form longer assemblies than its homochiral analogue have been rationalized at the molecular level.

Previously, we unravelled the self-assembly behaviour of homochiral ester BTA monomers derived from $\alpha$-amino esters (ester BTAs). ${ }^{8 b, 8 c}$ The nature of the dominant hydrogen-bonded chiral assemblies in solution, ester-bonded dimers or helical stacks, can be controlled by the nature of the substituent $\left(R^{1}\right.$ in Chart 1) and the experimental conditions (concentration, temperature). In particular, BTA (S)-Cha and BTA (S)-Val exclusively form dimers between $50 \mu \mathrm{M}$ and $90 \mathrm{mM}$. The molecular arrangement of these dimers, as depicted in Chart 1 , has been proposed previously based on spectroscopic analyses and Molecular Mechanics/Molecular Dynamics (MM/MD) calculations. ${ }^{8 c}$ We now report the X-ray crystal structures of BTA (S)-Cha ${ }^{i \text {-Pr }}$ (Figs. 1 and S1) and BTA (S)-Cha ${ }^{t-B u}$ (Fig. S2), which confirm our hypotheses. These structures are similar and show that the discrete dimers adopt a $D_{3}$ symmetry with several important structural features: i) a crossed hydrogen-bond pattern involving the amide $\mathrm{N}-\mathrm{H}$ and ester $\mathrm{C}=\mathrm{O}$ $(\mathrm{H} \cdots \mathrm{O}$ distances ranging from $2.154(3)$ to $2.277(3)$ 


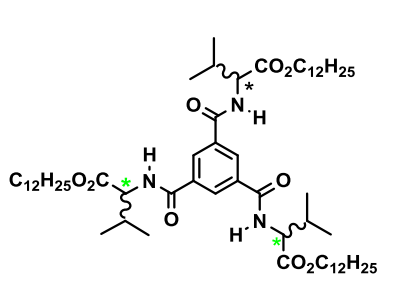

${ }^{*}=*=(S) ; \operatorname{BTA}(S)-\mathrm{Val}$ ${ }^{*}=(R),{ }^{*}=(S)$; BTA $(S, S, R)-\mathrm{Va}$ ${ }^{*}=*=($ rac $)$; BTA $(r a c)-V a l$

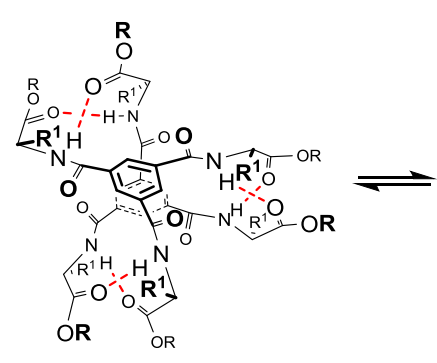

enantiopure dimers
$\mathrm{R}=\mathrm{C}_{12} \mathrm{H}_{25} ; \mathrm{BTA}(\mathrm{S})-\mathrm{Cha}$ $\mathrm{R}=i-\operatorname{Pr} ; \mathrm{BTA}(\mathrm{S})-\mathrm{Ch} a^{i-\mathrm{Pr}}$ $\mathrm{R}=t-\mathrm{Bu} ; \mathrm{BTA}(S)-\mathrm{Cha}^{t-\mathrm{Bu}}$

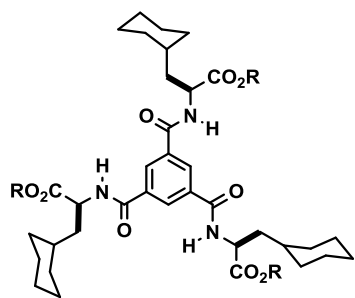

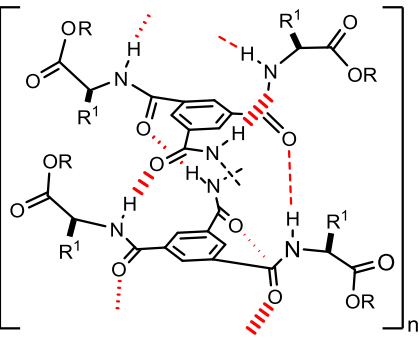

right-handed helical stacks (rod-like species)
Chart 1 Chemical structures of the 1,3,5-benzene tricarboxamide (BTA) monomers investigated in this study (top). Molecular structures of the enantiopure rod-like and dimeric hydrogen-bonded species formed by BTAs
derived from (S) $\alpha$-amino esters (ester BTAs, bottom). BTA (rac)-Val as obtained

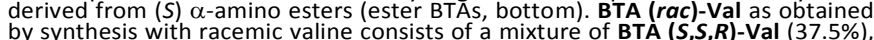
by synthesis with racemic valine consists of a mixture of BTA $(S, S, R)-$ V

$\AA$ A), ii) a distance between the centroids of the two stacked rings consistent with an aromatic interaction (3.468(1) and 3.502(1) $\AA$ ), and iii) a (P) planar chiral arrangement of the aromatic rings induced by the $(S)$ chirality of the peripheral amino ester groups. As a consequence of the geometrical constraints imposed by the hydrogen bonds, the alkyl ester moieties ( $i$-Pr or $t-\mathrm{Bu}$ ) and the cyclohexyl groups on the same BTA arm are directed in opposite directions and lie almost perpendicularly to the BTA aromatic rings. This leads to an alternate distribution of the cyclohexyl and alkyl ester groups at both upper and lower rims of the dimer (Figs. S1 and S2). Also, each aromatic $\mathrm{C}-\mathrm{H}$ hydrogen of one BTA is close to the atoms of one side chain belonging to the other BTA in the dimer. This is reflected by short distances between the aromatic $\mathrm{C}-\mathrm{H}$ hydrogens and the ester carbonyls belonging to the other BTA unit (ranging from 2.352(3) to 2.640(3) $\AA$ ) as well as between the aromatic hydrogens and other atoms (see caption in Figs. S1 and S2).

These X-ray structures will allow for a precise understanding of the factors determining the stability of the dimeric structure formed by ester BTAs, but before, it is important to verify that the main structural features of the dimeric structure in the solid state are maintained in solution. BTA $(S)$-Cha ${ }^{i-P r}$ displays virtually identical FT-IR spectra in the solid state and in solution (Fig. S3). Also, the ${ }^{1} \mathrm{H}$ NMR spectrum of BTA (S)-Cha ${ }^{i-\mathrm{Pr}}$ in $\mathrm{C}_{6} \mathrm{D}_{12}$ (Fig. S5) shows a single set of signals demonstrating that enantiomerically-pure dimeric assemblies are present in solution. The aromatic rings adopt a $(P)$ planar chirality as confirmed by the -/+/- pattern of the CD signals in the 200-260 $\mathrm{nm}$ region (Fig. S4). ${ }^{8 \mathrm{c}}$ This complete induction of the supramolecular chirality (observed both in the crystalline and solution states) is in accordance with the

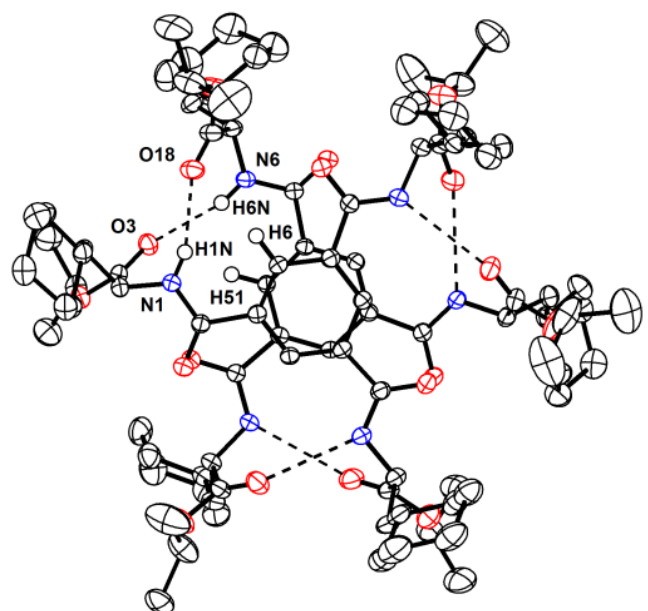

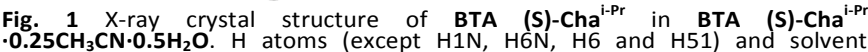

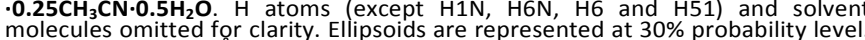
molecules omitted for clarity. Ellipsoids are represented at 30\% probability level. H51-03: 2.352(3).

energy difference between the $(P)$ and $(M)$ diastereomers calculated to be larger than $10 \mathrm{kcal}^{\mathrm{mol}} \mathrm{m}^{-1}$ for a related ester BTA. ${ }^{8 C}$ Finally, ROESY analyses were performed in $\mathrm{C}_{6} \mathrm{D}_{12}$ for BTA (S)-Cha ${ }^{i \text {-Pr }}$ in order to isolate atomic contacts that are specific to the dimer (Fig. S6). Remarkable dipolar couplings occur between the aromatic $\mathrm{C}-\mathrm{H}$ hydrogens (all equivalent) and: i) the hydrogen atom attached to the $\alpha$-carbon, ii) the methine hydrogen of the $i$-Pr group, and iii) one methyl of the $i$-Pr group. These contacts occur between the aromatic hydrogens of one BTA and the side chain of the other BTA within the dimeric structure. The NOE contacts observed in the 2D ROESY experiment are consistent with the distances between these atoms in the X-ray structure of BTA (S)-Cha ${ }^{i-P r}$ (all inferior to 4.5 $\AA$, Fig. S1). Taken all together, these analyses reveal that the dimeric structure is the same in the solid-state and in solution. $^{\ddagger}$

The tight interlocking of the two homochiral molecules in this dimeric structure offers the obvious prospect of trying to control its stability through stereochemical modifications. It seems likely that imposing a chiral mismatch in the molecular structure should destabilize the dimer.

In order to experimentally probe this stereochemical effect, BTA $(\boldsymbol{S}, \boldsymbol{S}, \boldsymbol{R})$-Val was synthesized. First, BTA (rac)-Val was prepared from trimesoyl chloride and a racemic mixture of the dodecyl ester of valine (see the SI+). Then, BTA $(\boldsymbol{S}, \boldsymbol{S}, \boldsymbol{R})$-Val was isolated from BTA (rac)-Val by means of preparative chiral HPLC (ee and de>99.5\%). + At low concentration ( $\leq 15 \mathrm{mM}$ ) in cyclohexane, BTA $(\boldsymbol{S}, \boldsymbol{S}, \boldsymbol{R})$-Val forms assemblies that resemble BTA (S)-Val dimers as shown by their similar FT-IR (10mM, Fig. S3) and CD spectra (2 mM, Fig. S4). Notably BTA $(\boldsymbol{S}, \boldsymbol{S}, \boldsymbol{R})$-Val show the same CD bands than BTA (S)-Val but of lower intensity as expected for a heterochiral system. The discrete nature of these assemblies is established by the fact that FT-IR (Fig. S8) and ${ }^{1} \mathrm{H}$ NMR (Fig. S9) analyses of BTA $(\boldsymbol{S}, \boldsymbol{S}, \boldsymbol{R})$-Val recorded at various concentrations are unchanged up to 15 $\mathrm{mM}^{\S}$ 


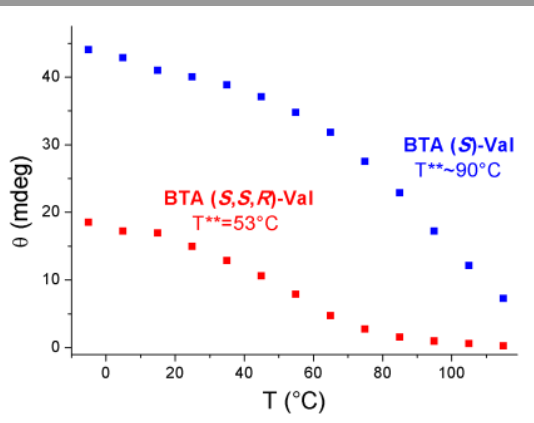

Fig. 2 Ellipticity $(\theta, 225 \mathrm{~nm})$ versus temperature for BTA $(\boldsymbol{S}, \boldsymbol{S}, \boldsymbol{R})$-Val and BTA (S)-Val (methylcyclohexane, $25 \mu \mathrm{M}$ ). The transition temperatures $\left(T^{* *}\right)$ between dimers and monomers are determined at the inflection point of the curves. These experiments have been performed in a closed quartz cell which explains why some of the measured temperatures exceed the boiling point of methylcyclohexane. For the full CD spectra see Fig. S13.

To gain information on the structure and stability of the potential dimers of BTA $(\boldsymbol{S}, \boldsymbol{S}, \boldsymbol{R})$-Val, we performed MM/MD calculations. ${ }^{\S \S}$ Three possible molecular arrangements were obtained, depending on the relative position of the $(R)$ ester side arms within the dimers (I-III, Fig. S10), and submitted to MD simulations of $10 \mathrm{~ns}$. These structures are of $C_{2}$ symmetry and have similar energies: accordingly we cannot ascertain the molecular arrangement of the heterochiral monomers in the dimers. Most importantly for the present study, they are all significantly less stable than the BTA $(S)$-Val ${ }^{\text {Me }}$ dimer (by 5.2 to $5.7 \mathrm{kcal}^{\mathrm{mol}}{ }^{-1}$, Table S1). An analysis of the energetic factors contributing to the destabilization of the dimers of BTA $(S, S, R)$ $\mathrm{Val}^{\mathrm{Me}}$ indicates that the hydrogen-bond energy decreases, but by only 0.5 to $1.4 \mathrm{kcal} / \mathrm{mol}$, i.e., by 4 to $11 \%$ of the initial value. Most of the penalty actually arises from the valence energy term (Table S1 and Figs. S11 and S12). In other terms, the chiral mismatch in the hydrogen-bonded arms slightly lowers the strength of some of the hydrogen bonds, but more importantly it imposes on the molecular backbone geometrical constraints that increase the energy of the dimeric structure.

Experimental evidence for the lower stability of the dimers of BTA $(\boldsymbol{S}, \boldsymbol{S}, \boldsymbol{R})$-Val compared to those of BTA (S)-Val was obtained by means of variable-temperature $C D$ analyses, to probe the transition between dimers and monomers in methylcyclohexane $(25 \mu \mathrm{M})$. For BTA $(\boldsymbol{S}, \boldsymbol{S}, \boldsymbol{R})$-Val, the intensity of the $C D$ signals rapidly decreases upon raising the temperature and only a vanishingly small $C D$ signal is present at $105^{\circ} \mathrm{C}$, which corresponds to the monomer (Fig. S13). ${ }^{8 \mathrm{C}}$ In contrast, full dissociation of the dimers is not observed for BTA (S)-Val. Plotting the ellipticity (measured at $225 \mathrm{~nm}$ ) as a function of the temperature yields a transition temperature of $53^{\circ} \mathrm{C}$ for BTA $(S, S, R)$-Val and of $c a .90^{\circ} \mathrm{C}$ for BTA (S)-Val (Fig. 2). The fact that the dimeric structure of $\operatorname{BTA}(S, S, R)$-Val is less stable than that of BTA (S)-Val has interesting consequences at higher concentrations. At $90 \mathrm{mM}, \mathrm{FT}-\mathrm{IR}$ shows that BTA $(\boldsymbol{S}, \boldsymbol{S}, \boldsymbol{R})$-Val almost exclusively forms the classical stacks stabilized by hydrogen bonds to the amide $\mathrm{C}=\mathrm{O}$, whereas $\mathrm{BTA}$ (S)-Val is still assembled into dimers (Fig. 3). As a result, the viscosity of the former solution increases markedly with the concentration (Fig. 4). For instance, a $30 \mathrm{mM}$ (4.0 wt\%)

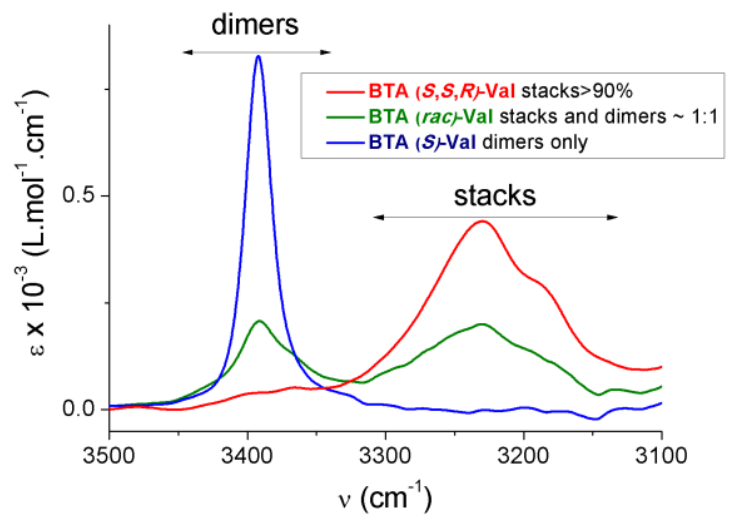

Fig. 3 FT-IR spectra of BTA $(S, S, R)$-Val, BTA (rac)-Val and BTA ( $S$ )-Val in cyclohexane (90 $\mathrm{mM}, 20^{\circ} \mathrm{C}$ ). Zoom on the $\mathrm{N}-\mathrm{H}$ region. For more details see Fig. S14.

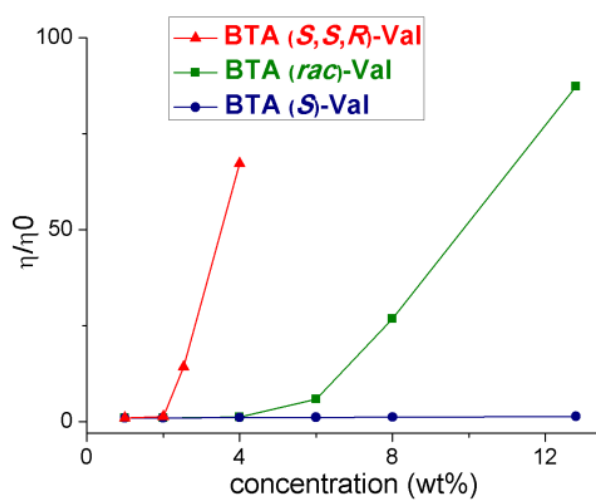

Fig. 4 Relative viscosity of BTA $(S, S, R)$-Val, BTA ( rac)-Val and BTA (S)-Val in cyclohexane versus concentration $\left(20^{\circ} \mathrm{C}\right)$.

cyclohexane solution of BTA $(\boldsymbol{S}, \boldsymbol{S}, \boldsymbol{R})$-Val is 60 times more viscous than that of BTA $(\boldsymbol{S})$-Val. This indicates that the drastically different self-assembly behaviour exhibited by the heterochiral monomer (BTA $(\boldsymbol{S}, \boldsymbol{S}, \boldsymbol{R})$-Val) compared to the homochiral one (BTA (S)-Val) has strong consequences on their macroscopic properties.

We finally turn our attention to the assembly properties of BTA (rac)-Val, which contains a large proportion of heterochiral monomers and is much easier to prepare than the pure heterochiral monomer. Following a statistical distribution of the enantiomers, BTA (rac)-Val is "racemic by synthesis" and is thus composed of the heterochiral monomers (BTA $(\boldsymbol{S}, \boldsymbol{S}, \boldsymbol{R})$-Val and BTA $(\boldsymbol{R}, \boldsymbol{R}, \boldsymbol{S})$-Val) and the homochiral monomers (BTA (S)-Val and BTA $(\boldsymbol{R})$-Val) in a 3:1 ratio. As expected, the viscosity of a BTA (rac)-Val solution is intermediate between those of BTA $(\boldsymbol{S}, \boldsymbol{S}, \boldsymbol{R})$-Val and BTA (S)-Val (Fig. 4). For example, a $90 \mathrm{mM}$ (12.9 wt\%) cyclohexane solution of BTA (rac)-Val is 87 times more viscous than a solution of BTA (S)-Val, while the BTA $(S, S, R)$-Val solution is too viscous to be measured with our capillary viscometer. BTA (rac)-Val forms an approximately 1:1 mixture of helical stacks and dimers at this concentration as deduced from FT-IR analyses (Fig. 3). These helical stacks are long, as indicated by the slope of the SANS intensity (Fig. S15) which is maintained down to the lowest $q$ values measured, meaning that a significant fraction of the stacks are longer than $200 \AA$. 
In conclusion, the structure of the chiral BTA assemblies can be tuned by modifying the stereochemistry of the BTA monomer. The heterochiral and the homochiral monomers both form a dimeric structure at low concentration, which transforms into long helical stacks only in the former molecule as a result of the lower stability of the chirally mismatched dimers. The strategy can potentially be applied to other types of monomers that self-assemble into two (or more) competing chiral supramolecular structures in solution.

This work was supported by the French Agence Nationale de la Recherche (project ANR-13-BS07-0021 SupraCatal). The GDR 3712 Chirafun is acknowledged for allowing a collaborative network between the partners of this project. Jacques Jestin (LLB, Saclay) is acknowledged for assistance with SANS experiments. Research in Mons is supported by the Science Policy Office of the Belgian Federal Government (BELSPO PAI 7/5) and FNRS-FRFC.

\section{Notes and references}

\# BTA (S)-Val forms the same dimers as BTA (S)-Cha ${ }^{i-P r}$, as evidenced by similar spectroscopic analyses (including similar NOE contacts, Fig. S7).

$\S$ FT-IR analyses of dimers of BTA $(\boldsymbol{S}, \boldsymbol{S}, \boldsymbol{R})$-Val (Fig. S8) show the presence of several superimposed $\mathrm{N}-\mathrm{H}$ absorption bands in the region between 3350 and $3450 \mathrm{~cm}^{-1}$ which we attribute the hydrogen bonds between the amide $\mathrm{N}-\mathrm{H}$ and the ester $\mathrm{C}=\mathrm{O}$ of different strength and to free $\mathrm{N}-\mathrm{H}$ bonds. ${ }^{1} \mathrm{H}$ NMR analyses of dimers of BTA $(\boldsymbol{S}, \boldsymbol{S}, \boldsymbol{R})$-Val (Fig. S9) are consistent with a $\boldsymbol{C}_{2}$ symmetric species since two different sets of signals in a $2 / 1$ relative intensity are present. These analyses do not allow us to ascertain the exact molecular arrangement of the monomers in the BTA $(S, S, R)$-Val dimers.

$\S \S$ Calculations were made on BTA $(S, S, R)-\mathrm{Val}^{\mathrm{Me}}$ and BTA $(S)$-Val ${ }^{\mathrm{Me}}$ with methyl ester groups instead of dodecyl ester groups in order to alleviate the computational cost.

1. (a) M. A. Mateos-Timoneda, M. Crego-Calama and D. N Reinhoudt, Chem. Soc. Rev., 2004, 33, 363; (b) A. R. A. Palmans and E. W. Meijer, Angew. Chem. Int. Ed., 2007, 46, 8948; (c) G. A Hembury, V. V. Borovkov and Y. Inoue, Chem. Rev., 2008, 108, 1 (d) D. K. Smith, Chem. Soc. Rev., 2009, 38, 684; (e) M. H. Liu, L. Zhang and T. Y. Wang, Chem. Rev., 2015, 115, 7304.

2. L. You, D. Zha and E. V. Anslyn, Chem. Rev., 2015, 115, 7840.

3. K. Shimomura, T. Ikai, S. Kanoh, E. Yashima and K. Maeda, Nat. Chem., 2014, 6, 429.

4. (a) J. J. D. de Jong, L. N. Lucas, R. M. Kellogg, J. van Esch and B. L. Feringa, Science, 2004, 304, 278; (b) J. Kim, J. Lee, W. Y. Kim, H. Kim, S. Lee, H. C. Lee, Y. S. Lee, M. Seo and S. Y. Kim, Nature. Commun., 2015, 6, 6959.

5. B. Narayan, K. K. Bejagam, S. Balasubramanian and S. J. George, Angew. Chem. Int. Ed., 2015, 54, 13053.

6. (a) T. Hasegawa, Y. Furusho, H. Katagiri and E. Yashima, Angew. Chem. Int. Ed., 2007, 46, 5885; (b) Q. X. Jin, L. Zhang, H. Cao, T. Y. Wang, X. F. Zhu, J. Jiang and M. H. Liu, Langmuir, 2011, 27, 13847; (c) M. Raynal, F. Portier, P. W. N. M. van Leeuwen and L. Bouteiller, J. Am. Chem. Soc., 2013, 135, 17687; (d) M. Raynal, P. Ballester, A. Vidal-Ferran and P. W. N. M. van Leeuwen, Chem. Soc. Rev., 2014, 43, 1660; (e) K. Ohmatsu and T. Ooi, Tetrahedron Lett., 2015, 56, 2043; (f) A. Desmarchelier, X. Caumes, M. Raynal, A. Vidal-Ferran, P. W. N. M. van Leeuwen and L. Bouteiller, J. Am. Chem. Soc., 2016, 138, 4908.
7. A. Brizard, R. Oda and I. Huc, Top. Curr. Chem., 2005, 256, 167. 8. (a) A. Aggeli, I. A. Nyrkova, M. Bell, R. Harding, L. Carrick, T. C. B. McLeish, A. N. Semenov and N. Boden, Proc. Natl. Acad. Sci. U. S. A., 2001, 98, 11857; (b) A. Desmarchelier, M. Raynal, P. Brocorens, N. Vanthuyne and L. Bouteiller, Chem. Commun., 2015, 51, 7397; (c) A. Desmarchelier, B. Giordano Alvarenga, X. Caumes, L. Dubreucq, C. Troufflard, M. Tessier, N. Vanthuyne, J. Idé, T. Maistriaux, D. Beljonne, P. Brocorens, R. Lazzaroni, M. Raynal and L. Bouteiller, Soft Matter, 2016, 12, 7824.

9. M. Yamauchi, T. Ohba, T. Karatsu and S. Yagai, Nature Commun., 2015, 6, 8936.

10. (a) A. Lohr and F. Wurthner, Isr. J. Chem., 2011, 51, 1052; (b) Y. Tidhar, H. Weissman, S. G. Wolf, A. Gulino and B. Rybtchinski, Chem. Eur. J., 2011, 17, 6068; (c) P. A. Korevaar, S. J. George, A. J. Markvoort, M. M. J. Smulders, P. A. J. Hilbers, A. P. H. J. Schenning, T. F. A. De Greef and E. W. Meijer, Nature, 2012, 481, 492; (d) P. A. Korevaar, T. F. A. de Greef and E. W. Meijer, Chem. Mater., 2014, 26, 576; (e) S. Ogi, T. Fukui, M. L. Jue, M. Takeuchi and K. Sugiyasu, Angew. Chem. Int. Ed., 2014, 53, 14363; (f) A. Sorrenti, R. Rodriguez-Trujillo, D. B. Amabilino and J. PuigmartíLuis, J. Am. Chem. Soc., 2016, 138, 6920.

11. (a) J. Hu, W. Kuang, K. Deng, W. Zou, Y. Huang, Z. Wei and C. F. J. Faul, Adv. Funct. Mater., 2012, 22, 4149; (b) M. A. J. Gillissen, M. M. E. Koenigs, J. J. H. Spiering, J. A. J. M. Vekemans, A. R. A. Palmans, I. K. Voets and E. W. Meijer, J. Am. Chem. Soc., 2014, 136, 336; (c) L. Đorđević, T. Marangoni, T. Miletić, J. RubioMagnieto, J. Mohanraj, H. Amenitsch, D. Pasini, N. Liaros, S. Couris, N. Armaroli, M. Surin and D. Bonifazi, J. Am. Chem. Soc., 2015, 137, 8150.

12. Y. Cai, Z. Guo, J. Chen, W. Li, L. Zhong, Y. Gao, L. Jiang, L. Chi, H. Tian and W.-H. Zhu, J. Am. Chem. Soc., 2016, 138, 2219.

13. (a) R. Oda, I. Huc, M. Schmutz, S. J. Candau and F. C. MacKintosh, Nature, 1999, 399, 566; (b) M. Kumar, P. Brocorens, C. Tonnelé, D. Beljonne, M. Surin and S. J. George, Nature Commun., 2014, 5, 5793; (c) A. Brizard, C. Aimé, T. Labrot, I. Huc, D. Berthier, F. Artzner, B. Desbat and R. Oda, J. Am. Chem. Soc., 2007, 129, 3754.

14. M. M. Safont-Sempere, G. Fernández and F. Würthner, Chem. Rev., 2011, 111, 5784.

15. (a) J. H. Fuhrhop, P. Schnieder, J. Rosenberg and E. Boekema, J. Am. Chem. Soc., 1987, 109, 3387; (b) J. Makarević, M. Jokić, Z. Raza, Z. Štefanić, B. Kojić-Prodić and M. Žinić, Chem. Eur. J., 2003, 9, 5567; (c) A. R. Hirst, D. K. Smith, M. C. Feiters and H. P. M. Geurts, Chem. Eur. J., 2004, 10, 5901; (d) Y. Watanabe, T. Miyasou and M. Hayashi, Org. Lett., 2004, 6, 1547; (e) D. Ogata, T. Shikata and K. Hanabusa, J. Phys. Chem. B, 2004, 108, 1550315510. (f) T. Shikata, Y. Kuruma, A. Sakamoto and K. Hanabusa, J. Phys. Chem. B, 2008, 112, 16393-16402. (g) R. Amemiya, M. Mizutani and M. Yamaguchi, Angew. Chem. Int. Ed., 2010, 49, 1995; (h) X. F. Zhu, Y. G. Li, P. F. Duan and M. H. Liu, Chem. Eur. J., 2010, 16, 8034; (i) K. J. Nagy, M. C. Giano, A. Jin, D. J. Pochan and J. P. Schneider, J. Am. Chem. Soc., 2011, 133, 14975; (j) Z. C. Shen, T. Y. Wang and M. H. Liu, Langmuir, 2014, 30, 10772.

16. (a) T. Naota and H. Koori, J. Am. Chem. Soc., 2005, 127, 9324; (b) T. Koga, M. Matsuoka and N. Higashi, J. Am. Chem. Soc., 2005, 127, 17596; (c) J. Kumar, H. Tsumatori, J. Yuasa, T. Kawai and T. Nakashima, Angew. Chem. Int. Ed., 2015, 54, 5943.

17. (a) V. Percec and P. Leowanawat, Isr. J. Chem., 2011, 51, 1107; (b) C. Roche, H. J. Sun, P. Leowanawat, F. Araoka, B. E. Partridge, M. Peterca, D. A. Wilson, M. E. Prendergast, P. A. Heiney, R. Graf, H. W. Spiess, X. B. Zeng, G. Ungar and V. Percec, Nature Chem., 2016, 8, 80. 